\title{
Design, Tuning and Analysis of a Robust PID Controller for FOPTD Unstable Systems with Uncertainty in the Process Model Parameters
}

\begin{abstract}
Vivek B. Patil ${ }^{1}$, Prof Dr. Dilip K. Maghade ${ }^{2}$
PG Student, Department of Instrumentation Engineering, Vishwakarma Institute of Technology, Pune, India ${ }^{1}$

Associate Professor, Department of Instrumentation Engineering, Vishwakarma Institute of Technology, Pune, India ${ }^{2}$

Abstract: In this paper, extensive simulations are performed on the FOPTD Unstable systems having uncertain process model parameters (i.e process gain $(\mathrm{Kp})$, time constant $(\tau)$ and dead time $\left(\mathrm{t}_{\mathrm{d}}\right)$, in order to design a robust PI/PID controller with better disturbance rejection and servo response, without compromising the robust performance (Robust stability) of the system. A simple PI/PID controller design and tuning method is described and compared from the point of view of the control system robustness for the First order plus time delay (FOPTD) process. For FOPTD Un-stable systems, the step responses obtained by the proposed method when uncertainty in the process model parameters exist, are compared to the responses obtained by Visioli [3], IMC(Wang/Hang)[5] and Huang-Chen [2] methods. The Proposed controller settings give a robust performance for uncertainty in model parameters. The performance of PID tuning techniques is analyzed and compared on basis of minimization of error and transient response specifications. A theoretical analysis of robustness and stability of the proposed controller is done using Kharitonov's theorem (Barmish) [4] to validate the simulation results obtained using MATLAB/SIMULINK.
\end{abstract}

Keywords: PI/PID, FOPTD systems, Robustness, Uncertainty, Kharitonov's theorem.

\section{INTRODUCTION}

The design of a controller depends on a model of the process. If the controller is installed on a process whose parameters are not exactly the same as the model used to design the controller, what happens to its performance? Is the system unstable? Is it too under damped or too slow? These are very practical questions. If a control system is tolerant to changes in process parameters, it is called Robust. Robust control refers to the control of unknown plants with unknown dynamics subject to unknown disturbances. It must be recognized that some performance may be sacrificed in order to guarantee that the system meets certain requirements. The design of PID controllers for unstable FOPTD model has attracted attention recently. R.Padma Sree and M.Chidambaram [1] had proposed a simple method based on matching the coefficients of the powers of ' $\mathrm{s}$ ' in the numerator and the denominator of the closed loop transfer function for Stable and Unstable systems. In present paper, using MATLAB/Simulink simulation is performed for varying levels of uncertainties in the process model parameters of a FOPTD plant, in order to determine the stability ranges. The robustness of the closed loop system for the perturbation, separately in time delay $\left(\mathrm{t}_{\mathrm{d}}\right)$, time constant $(\tau)$ and process gain $(\mathrm{Kp})$ is analyzed theoretically by Kharitonov's method(Barmish) [4]. For validation of the simulated responses, a comparative study is performed between the simulated results and the theoretical results.

\section{LITERATURE SURVEY}

Mathematical models invariably give an imperfect description of physical systems, and, in any case, the parameters involved in such a description are often subject to variation and uncertainty. In the analysis stage it is therefore important to assess the sensitivity of the system stability and performance to parameter variations, and, in the design stage, it is desirable to minimize this sensitivity and thus aim for insensitive or robust control schemes. It was Bode who laid the foundations to robust feedback design. Despite this major contribution, the subject went into virtual hibernation until the early 1960s, when Horowitz launched his frequency response approach to robustness [8]. His pioneering work evolved into a quantitative feedback theory and led to a successful design method. With regard to the design and tuning of PID controllers, there are many methods that can be found in the literature over the last seventy years. In fact, since Ziegler and Nichols (1942) presented their PID tuning rules, a huge number of procedures have been developed, using different approaches to deal with a variety of control problems. The methods for designing PID controllers for unstable FOPTD systems are given by the modified Ziegler-Nichols (Z-N) method (DePaor \& O’Malley, 1989; Ho \& $\mathrm{Xu}$, 1998; Venkatasubramaniam \& Chidambaram, 1994), IMC method (Marchetti, Scali, \& Lewin, 2001; Rotstein \& Lewin, 1991), pole placement method (Clement \& Chidambaram, 1997a, 1997b), optimization method (Cheng \& Hwang, 1998; Manoj \& Chidambaram, 2001; Visioli, 2001), two degrees of freedom method (Huang and Chen, 1997, 1999) and synthesis method (Chandrashekar, Padmasree, and Chidambaram, 2002; Jung, Song, and Hyun, 1999). In many of these methods, one or two adjustable parameters are used to calculate the PID settings. In the present paper, a simple method(i.e $\alpha_{1}$ and $\beta$ ) adjustable tuning parameters is analyzed and simulations are performed for obtaining stability ranges and robustness of the proposed method. 


\section{PROPOSED METHOD}

\section{A) PID controller for Un-stable system}

In the present section, a PID controller is designed for Unstable FOPTD system using two tuning parameters (i.e $\alpha_{1}$ and $\beta$ ).Let us consider a FOPTD system,

$$
\mathrm{G}(\mathrm{s})=\frac{\mathrm{Kp} * \mathrm{e}^{-\mathrm{td} . \mathrm{s}}}{\tau \mathrm{s}-1}
$$

with '+' sign for stable systems and

'-' sign for unstable systems.

Let us consider a PID controller. The PID control law is given by,

$$
\frac{\mathrm{u}(\mathrm{s})}{\mathrm{e}(\mathrm{s})}=\mathrm{Kc} *\left[1+\frac{1}{\tau i * \mathrm{~s}}+\tau \mathrm{D} * \mathrm{~s}\right]
$$

Where,

$\mathrm{u}$ is manipulated variable and

e is error.

The closed loop transfer function relating the output variable (y) to the set point (r) is give by,

$$
\frac{\mathrm{y}(\mathrm{s})}{\mathrm{r}(\mathrm{s})}=\frac{\mathrm{C}(\mathrm{s}) * \mathrm{G}(\mathrm{s})}{1+\mathrm{C}(\mathrm{s}) * \mathrm{G}(\mathrm{s})}
$$

On simplification we get the following equation $\frac{\mathrm{y}(\mathrm{s})}{\mathrm{r}(\mathrm{s})}=$

$$
\left[\left(\mathrm{Kc} * \mathrm{Kp} * \tau \mathrm{D} * \tau * \mathrm{~s}^{2} * \mathrm{e}^{-\mathrm{td} * \mathrm{~s}}\right)+\left(\mathrm{Kc} * \mathrm{Kp} * \tau * \mathrm{~s} * \mathrm{e}^{-\mathrm{td} * \mathrm{~s}}\right)+\left(\frac{\mathrm{Kc} * \mathrm{Kp} * \tau * \mathrm{e}^{-\mathrm{td} * \mathrm{~s}}}{\tau \mathrm{i}}\right)\right]
$$

$\left[\tau^{2} * \mathrm{~s}^{2}-\tau * \mathrm{~s}+\left(\mathrm{Kc} * \mathrm{Kp} * \tau \mathrm{D} * \tau * \mathrm{~s}^{2} * \mathrm{e}^{-\mathrm{td} * \mathrm{~s}}\right)+\left(\mathrm{Kc} * \mathrm{Kp} * \tau * \mathrm{~s} * \mathrm{e}^{-\mathrm{td} * \mathrm{~s}}\right)+\left(\frac{\mathrm{Kc} * \mathrm{Kp} * \tau * \mathrm{e}^{-\mathrm{td} * \mathrm{~s}}}{\tau \mathrm{i}}\right)\right.$

Now using the following substitutions in Eq.(4),

$$
\begin{aligned}
& \mathrm{Kc} \cdot \mathrm{Kp}=\mathrm{k} 1 \\
& \mathrm{k} 1 * \frac{\tau}{\tau \mathrm{i}}=\mathrm{k} 2 \\
& \mathrm{k} 1 * \frac{\tau \mathrm{D}}{\tau}=\mathrm{k} 3 \\
& \frac{\mathrm{td}}{\tau}=\in \\
& \mathrm{s}=\frac{\mathrm{q}}{\tau}
\end{aligned}
$$

and by further simplification we get the following equation in terms of powers of ' $\mathrm{q}$ ',

$$
\frac{\mathrm{y}(\mathrm{s})}{\mathrm{r}(\mathrm{s})}=\left[\mathrm{k} 1 \mathrm{q}+\mathrm{k} 2+\mathrm{k} 3 \mathrm{q}^{2}\right] * \frac{\mathrm{e}^{-\epsilon \mathrm{q}}}{(\mathrm{q}-1) \mathrm{q}+\left(\mathrm{k} 1 \mathrm{q}+\mathrm{k} 2+\mathrm{k} 3 \mathrm{q}^{2}\right) \mathrm{e}^{-\epsilon \mathrm{q}}}
$$

The Eq. (10) can be written as,

$$
\frac{Y(q)}{Y r(q)}=\left[k 1 q+k 2+k 3 q^{2}\right] * e^{0.5 \in q} * \frac{e^{-\in q}}{(q-1) q^{* 0.5} e^{0}+\left(k 1 q+k 2+k 3 q^{2}\right) e^{-0.5 \epsilon q}}
$$

Using the Taylor series expansion for $e^{0.5(\epsilon . q)}$ and $e^{-0.5(\epsilon . q)}$, we simplify the numerator and denominator terms of the above equation. Equating the coefficient of power of ' $q$ ' to ' $\alpha_{1}$ ' times that of the denominator whereas the coefficient of $\mathrm{q}^{2}$ and $\mathrm{q}^{3}$ is set to ' $\alpha_{2}$ ' times that of the denominator. Here $\alpha_{2}=\beta . \alpha_{1}$.We simplify the above equation to obtain a set of linear algebraic equations for the PID controller settings:

$\left[\begin{array}{ccc}1-\alpha 1 & 0.5 \epsilon(1+\alpha 1) & 0 \\ 0.5 \epsilon(1+\alpha 2) & 0.125 \epsilon^{2}(1-\alpha 2) & 1-\alpha 2 \\ 0.25 \epsilon(1-\alpha 2) & 0.25(1+\alpha 2) \epsilon^{2} / 6 & 1+\alpha 2\end{array}\right]\left[\begin{array}{l}\mathrm{k} 1 \\ \mathrm{k} 2 \\ \mathrm{k} 3\end{array}\right]=\left[\begin{array}{c}-\alpha 1 \\ \alpha 2(1-0.5 \epsilon) \\ \alpha 2(1-0.25 \epsilon)\end{array}\right]$

Here ' $\alpha_{1}$ ' and ' $\beta$ ' are the tuning parameters.
To make the tuning procedure simple, the value of $\beta$ is kept as 0.6 .Hence there is only one tuning parameter $\alpha 1$. PID settings are tuned for different values of ' $\epsilon$ ' using simulation. Here the value of $\alpha 1$ is obtained as 2.4 by simulation for plant under study, having following process parameters: $\mathrm{Kp}=1, \tau=1$ and $\mathrm{t}_{\mathrm{d}}=0.5$. On solving the above linear algebraic equations, we obtain the values of the variables $\mathrm{k} 1, \mathrm{k} 2$ and $\mathrm{k} 3$. By using the following formulae's we can calculate the controller settings:

$$
\begin{aligned}
\mathrm{Kc} & =\frac{\mathrm{k} 1}{\mathrm{Kp}} \\
\tau \mathrm{i} & =\tau \cdot \frac{\mathrm{k} 1}{\mathrm{k} 2} \\
\tau \mathrm{D} & =\tau \cdot \frac{\mathrm{k} 3}{\mathrm{k} 1}
\end{aligned}
$$

\section{B) Simulation results and observations:}

\begin{tabular}{|c|c|c|c|c|}
\hline Method & Kc & $\tau i$ & $\tau D$ & $\begin{array}{c}\text { Filter } \\
\text { Time } \\
\text { constant }\end{array}$ \\
\hline Proposed & 2.1904 & 2.7933 & 0.2546 & - \\
\hline $\begin{array}{l}\text { Huang- } \\
\text { Chen }\end{array}$ & 2.142 & 2.9087 & 0.1603 & - \\
\hline IMC & 2.444 & 5.5 & 0.2386 & 0.05 \\
\hline Visioli & 2.4976 & 2.8879 & 0.2901 & - \\
\hline
\end{tabular}

Let us consider an Unstable FOPTD system with $\mathrm{Kp}=1, \tau$ $=1$ and $t_{d}=0.5$. For performance comparison, we use the servo and regulatory responses obtained by IMC(Wang/Hang)[5], Huang-Chen[2] and Visioli [3] mehods for analysis. Here the tuning parameters are set as $\alpha_{1}=2.4$ and $\beta=0.6$.For robustness analysis, perturbations are introduced in the model parameters and responses are recorded to analyse the stability of the system. The controller settings for the Proposed method [1] ,HuangChen[2], IMC(Wang/Hang)[5] and Visioli [3] method are given the table below:

TABLE I Controller settings for FOPTD Process with $\mathrm{Kp}=1, \tau=1$ AND $\mathrm{t}_{\mathrm{d}}=0.5$

\section{Case 1: For $K p=1, \tau=1$ and $t_{d}=0.5$}

A comparative analysis of the performance of the controllers is performed based on the Minimization of the Integral error i.e (ISE and IAE) and by comparing the Transient response specifications of the servo responses.Fig. 1 and Fig. 2 shows the servo and regulatory responses of the closed loop system respectively using the Proposed controller [1], Huang-Chen [2], Visioli [3] and IMC(Wang/Hang)[5] controller. Table II shows the Transient response specifications and the ISE/IAE values for different controllers.

TABLE II ISE/IAE values and Transient response specifications for $\mathrm{Kp}=1, \tau=1$ AND $\mathrm{t}_{\mathrm{d}}=0.5$

\begin{tabular}{|l|l|l|l|l|l|}
\hline Method & $\begin{array}{l}\text { OS } \\
(\%)\end{array}$ & $\begin{array}{l}\text { Ts } \\
(\mathbf{s e c})\end{array}$ & $\begin{array}{l}\text { Tr } \\
(\mathbf{s e c})\end{array}$ & ISE & IAE \\
\hline Proposed & 135 & 6.43 & 0.116 & 2.4806 & 2.9964 \\
\hline $\begin{array}{l}\text { Huang- } \\
\text { Chen }\end{array}$ & 168 & 4.2 & 0.175 & 2.8709 & 3.0461 \\
\hline IMC & 175 & 9.13 & 0.648 & 3.515 & 3.9909 \\
\hline Visioli & 159 & 7.26 & 0.0823 & 3.1066 & 2.9296 \\
\hline
\end{tabular}


From Table I we can see that, under perfect parameter the other controllers.

conditions the Proposed controller has a small overshoot Thus under perfect parameter conditions, the Proposed compared to that of IMC and Visioli methods. The Huang- method[1] gives best performance compared to that of Chen method has a very small settling time $\left(t_{s}\right)$ than that of IMC(Wang/Hang)[5] and Huang-Chen[2] methods. Proposed controller as shown in Table II. But the Though Visioli [3] method gives a large overshoot, it Proposed controller gives better ISE and IAE values than gives better performance for ISE, and IAE values.

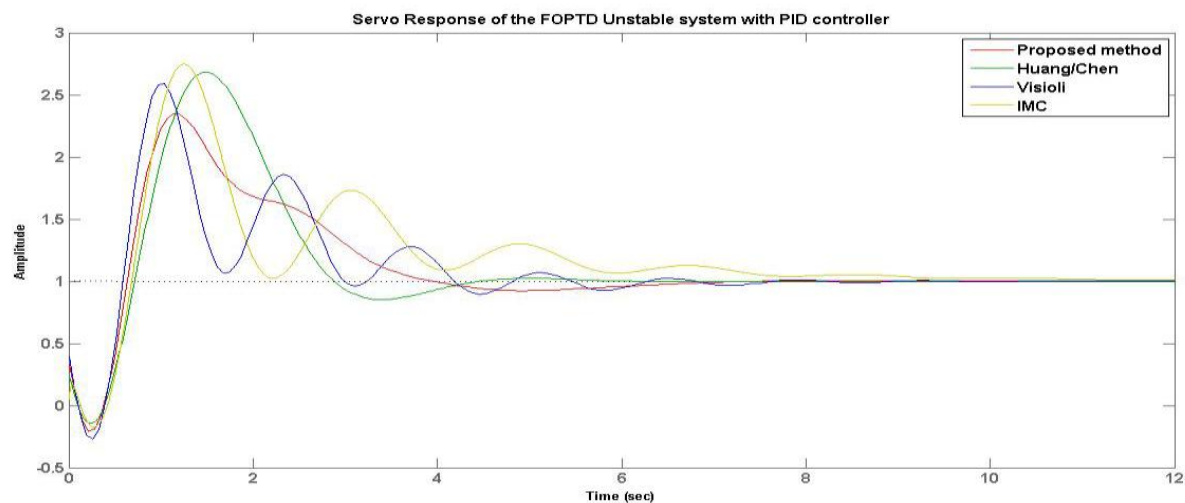

Fig. 1 Comparison of servo responses of FOPTD Un-stable system $\left(\mathrm{Kp}=1, \tau=1\right.$ and $\left.\mathrm{t}_{\mathrm{d}}=0.5\right)$

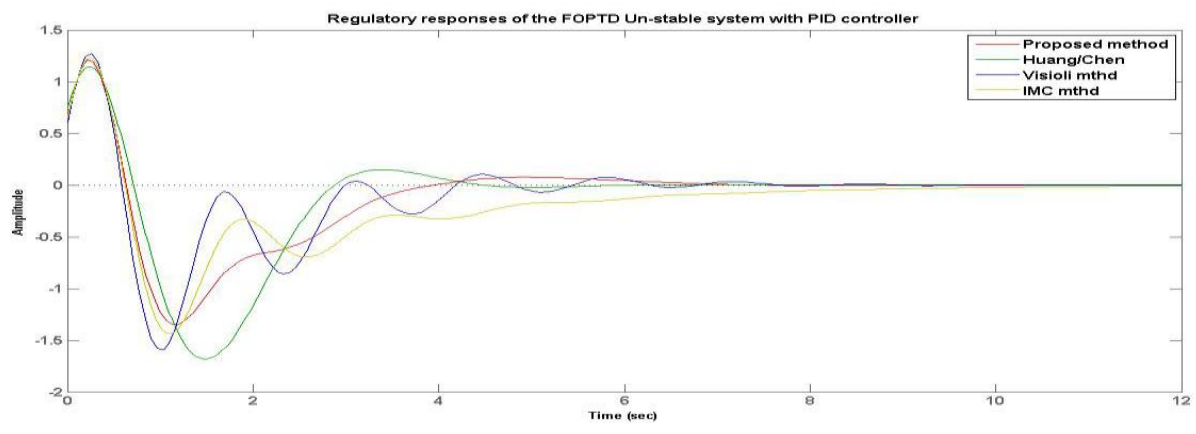

Fig. 2 Comparison of Regulatory responses of FOPTD Un-stable system $\left(\mathrm{Kp}=1, \tau=1\right.$ and $\left.\mathrm{t}_{\mathrm{d}}=0.5\right)$

Case 2: For $\mathrm{Kp}=1.2, \tau=1$ and $\mathrm{t}_{\mathrm{d}}=\mathbf{0 . 5}$

Here controller settings are set as shown in TableI. The tuning parameters are set as $\alpha_{1}=2.4$ and $\beta=0.6$. The robustness of the controller is evaluated by perturbing the process gain $(\mathrm{Kp})$ as 1.2 in the process, whereas the controller settings used are for $\mathrm{Kp}=1$.

For uncertainty of $+20 \%$ in Process gain Kp , the Visioli method gives unstable response as shown in Fig.3.
The IMC method gives highly oscillatory response and settling time $\left(t_{s}\right)$ to reach the steady state is very large. Huang-Chen method gives better settling time $\left(t_{\mathrm{s}}\right)$ and ISE value than that of the proposed controller. But the response of the Huang-Chen method to step load disturbance is slow as shown in Fig.4 below. The Proposed controller gives satisfactory servo response and desirable property of disturbance rejection.

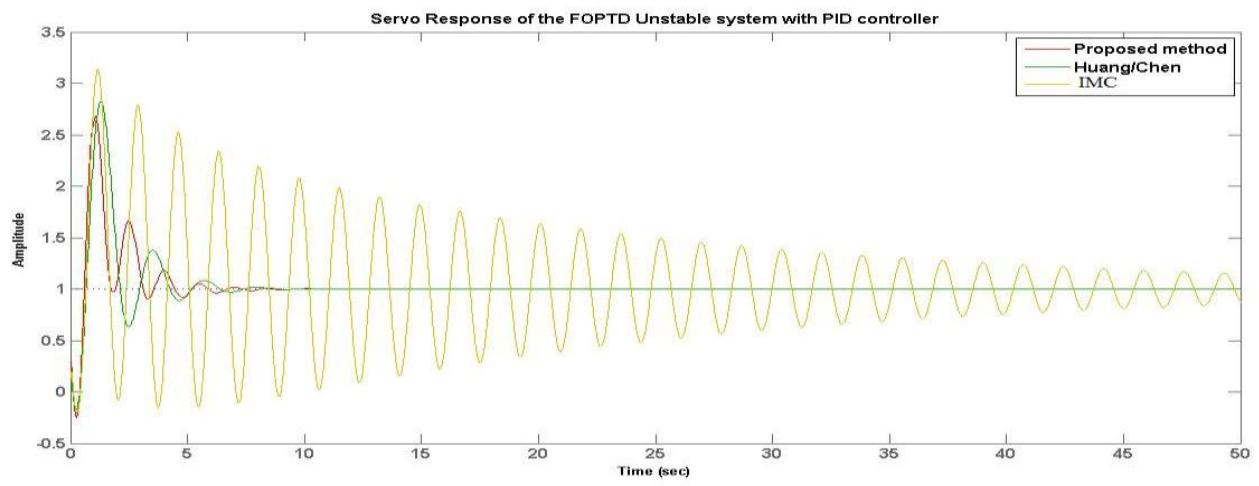

Fig. 3 Comparison of Servo responses of FOPTD Un-stable system $\left(K p=1.2, \tau=1\right.$ and $\left.t_{d}=0.5\right)$ 


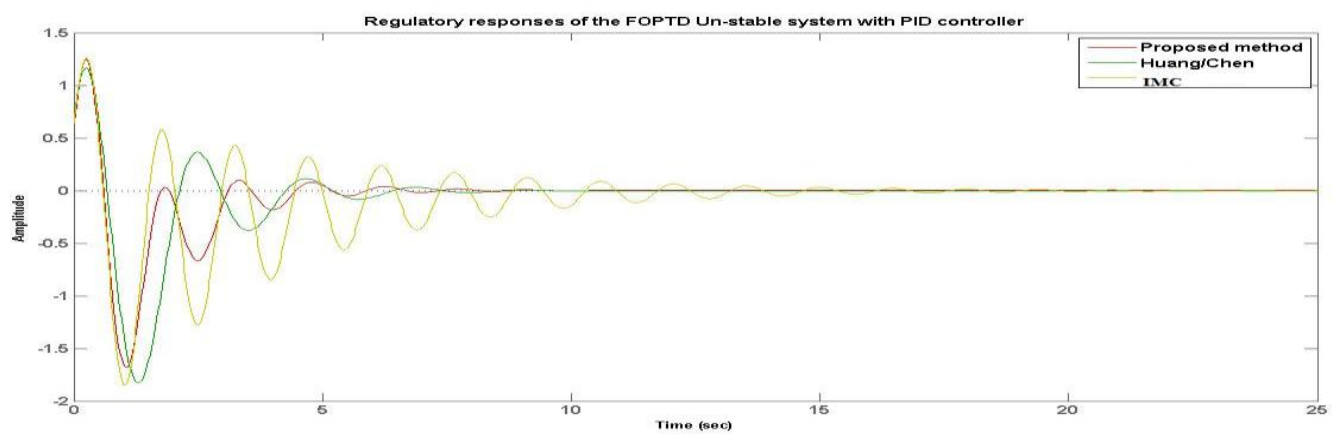

Fig.4 Comparison of Regulatory responses of FOPTD Un-stable system $\left(\mathrm{Kp}=1.2, \tau=1\right.$ and $\left.\mathrm{t}_{\mathrm{d}}=0.5\right)$

Fig. 3 and Fig.4 show the servo and regulatory responses. For an Uncertainty of +0.2 in the process gain $(\mathrm{Kp})$, Visioli [3] method could not stabilise the system. Proposed method [1] leads to better disturbance rejection. Table III below shows the comparison of time domain specifications and ISE, IAE values. Here, 'U' implies Unstable.

TABLE III ISE/IAE values and Transient response

\begin{tabular}{|l|l|l|l|l|l|}
\hline Method & $\begin{array}{l}\text { OS } \\
(\boldsymbol{\%})\end{array}$ & $\begin{array}{l}\mathbf{t}_{\mathbf{s}} \\
(\mathbf{s e c})\end{array}$ & $\mathbf{t}_{\mathbf{r}}(\mathbf{s e c})$ & ISE & IAE \\
\hline Proposed & 168 & 6.37 & 0.0877 & 3.1661 & 2.7535 \\
\hline $\begin{array}{l}\text { Huang- } \\
\text { Chen }\end{array}$ & 182 & 6.18 & 0.138 & 2.4775 & 2.7502 \\
\hline IMC & 214 & 76 & 0.62 & $\begin{array}{l}17.566 \\
7\end{array}$ & $\begin{array}{l}23.829 \\
3\end{array}$ \\
\hline Visioli & $\mathrm{U}$ & $\mathrm{U}$ & $\mathrm{U}$ & $\mathrm{U}$ & $\mathrm{U}$ \\
\hline
\end{tabular}
specifications for $\mathrm{Kp}=1.2, \tau=1$ AND $\mathrm{t}_{\mathrm{d}}=0.5$

\section{Case 3: For $\mathrm{Kp}=1,=0.8$ and $\mathrm{td}=0.5$}

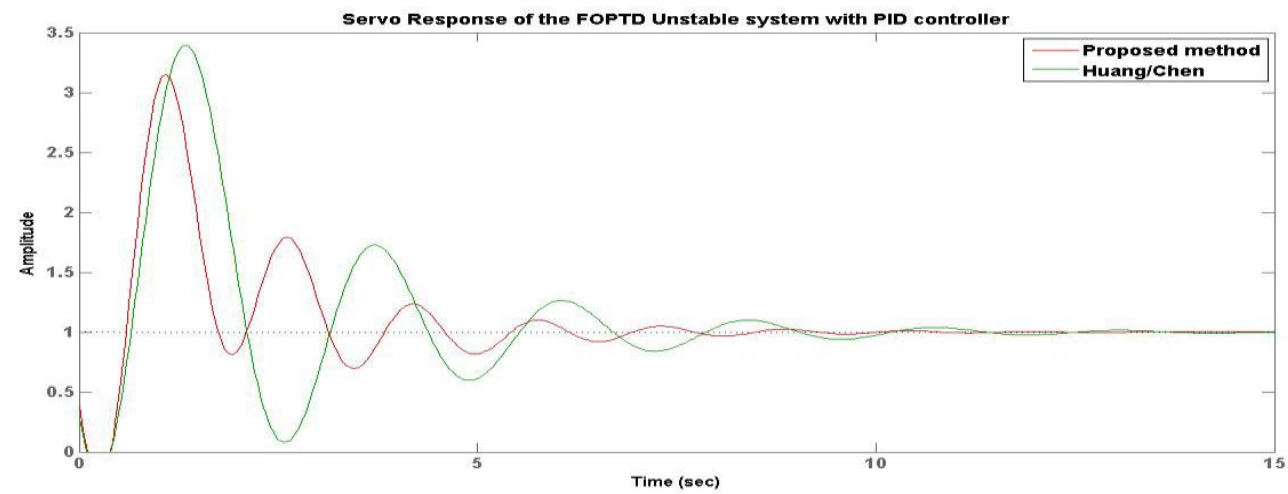

Fig.5 Comparison of Regulatory responses of FOPTD Un-stable system $\left(\mathrm{Kp}=1.2, \tau=1\right.$ and $\left.\mathrm{t}_{\mathrm{d}}=0.5\right)$

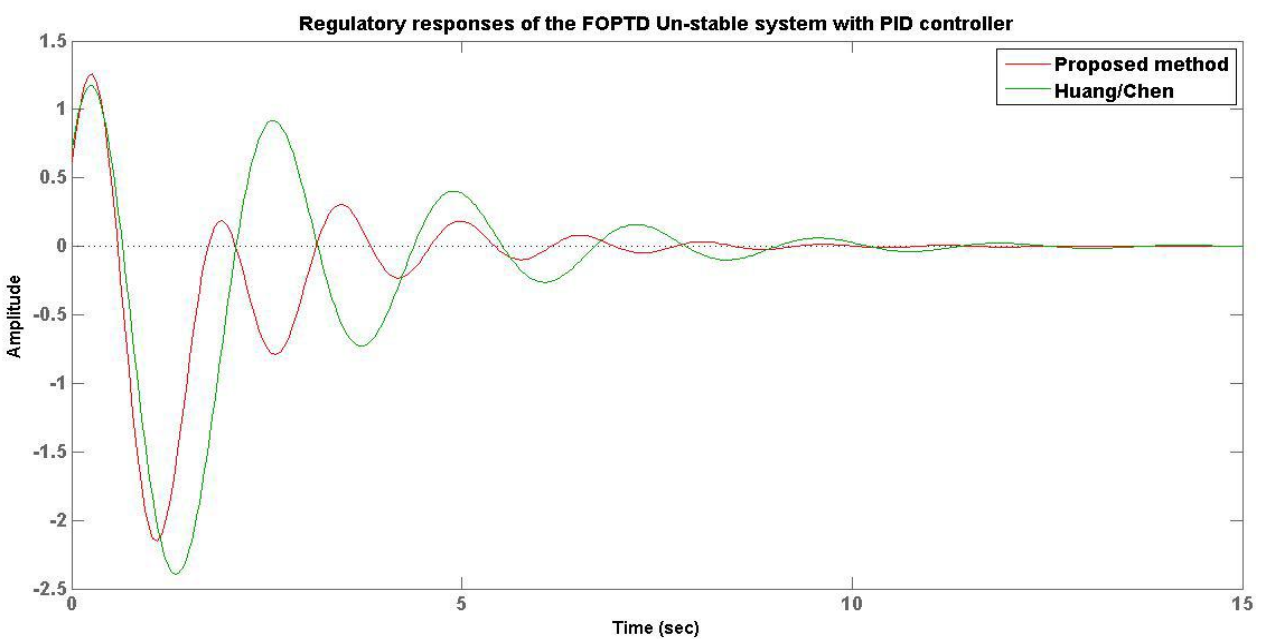


Fig.5 and Fig.6 shows the servo and regulatory responses respectively. When a perturbation of 0.8 is introduced in the system time constant().IMC(Wang/Hang)[5] and Visioli[3] system lead to unstable response. The Proposed method [1] and the Huang-Chen[2] method gives excellent servo response, but the Huang-Chen[2] method gives large overshoot and settling time. Also the Proposed method[1] leads to better regulatory response than the Huang-Chen method. Table IV below shows the comparison of time domain specifications and ISE, IAE values. Here,' U' implies Unstable.

TABLE IV ISE/IAE values and Transient response specifications for FOR Kp=1, $=0.8$ AND td $=0.5$

\begin{tabular}{|l|l|l|l|l|l|}
\hline Method & $\begin{array}{l}\text { OS } \\
(\boldsymbol{\%})\end{array}$ & $\begin{array}{l}\text { Ts } \\
\text { (sec) }\end{array}$ & $\begin{array}{l}\text { Tr } \\
(\mathbf{s e c})\end{array}$ & ISE & IAE \\
\hline Proposed & 215 & 7.43 & 0.0812 & 4.7851 & 3.5448 \\
\hline $\begin{array}{l}\text { Huang- } \\
\text { Chen }\end{array}$ & 240 & 9.82 & 0.127 & 4.1708 & 4.6317 \\
\hline IMC & U & U & U & U & U \\
\hline Visioli & U & U & U & U & U \\
\hline
\end{tabular}

\section{B. Robustness Analysis}

Kharitonov's theorem (Barmish)[4] is a result used in control theory to assess the stability of a dynamical system when the physical parameters of the system are not known precisely. When the coefficients of the characteristic polynomial are known, the Routh-Hurwitz stability criterion can be used to check if the system is stable (i.e. if all roots have negative real parts).To compare the robustness of the different controller design methods, the range of uncertainty in each of the model parameters for which the controller is stable is to be calculated. In this method, the stability of four equations formed from Kharitonov polynomials is to be checked.

The characteristic equation of the system using second order Pades approximation for delay is,

$$
1+C(s) * G(s)=0
$$

From Eq.(3a) the characteristic polynomial is,

$$
\begin{aligned}
& {\left[\tau^{2} * \mathrm{~s}^{2}-\tau * \mathrm{~s}+\left(\mathrm{Kc} * \mathrm{Kp} * \tau \mathrm{D} * \tau * \mathrm{~s}^{2} * \mathrm{e}^{-\mathrm{td} * \mathrm{~s}}\right)+\right.} \\
& \left.\left(\mathrm{Kc} * \mathrm{Kp} * \tau * \mathrm{~s} * \mathrm{e}^{-\mathrm{td} * \mathrm{~s}}\right)+\left(\frac{\mathrm{Kc} * \mathrm{Kp} * \tau * \mathrm{e}^{-\mathrm{td} * \mathrm{~s}}}{\tau \mathrm{i}}\right)\right]=0
\end{aligned}
$$

The equation (8a) can be simplified to following form, $\mathrm{a} 0+\mathrm{a} 1 \cdot \mathrm{s}+\mathrm{a} 2 \cdot \mathrm{s}^{2}+\mathrm{a} 3 \cdot \mathrm{s}^{3}+\mathrm{a} 4 \cdot \mathrm{s}^{4}=0$

Where,

$\mathrm{a} 0=\mathrm{Kc} * \mathrm{Kp}$

$\mathrm{a} 1=\mathrm{Kc} * \mathrm{Kp}[\tau \mathrm{i}-(0.5 . \mathrm{td})]-\tau \mathrm{i}$

$\mathrm{a} 2=\mathrm{Kc} * \mathrm{Kp}\left[(\tau \mathrm{D} . \tau \mathrm{i})-(0.5 . \mathrm{td}) \tau \mathrm{i}+(0.0833) \mathrm{td}^{2}\right]+\tau \mathrm{i} . \tau$

- (0.5.td) $\tau \mathrm{i}$

$\mathrm{a} 3=\mathrm{Kc} * \operatorname{Kp}\left[\left(0.0833 \mathrm{td}^{2} \cdot \tau \mathrm{i}\right)-(0.5 \cdot \mathrm{td} \cdot \tau \mathrm{D} \cdot \tau \mathrm{i})\right]+$

(0.5. td. $\tau$ i. $\tau)-\left(0.0833 \tau\right.$ i. td $^{2}$

$\mathrm{a} 4=\left[0.0833 \mathrm{Kc} * \operatorname{Kp}\left(\tau \mathrm{D} . \tau \mathrm{i} \cdot \mathrm{td}^{2}\right)\right]+0.0833\left(\tau . \tau \mathrm{i} \cdot \mathrm{td}^{2}\right)$

Kharitonovs equations for $\mathrm{a}_{\mathrm{i}}{ }^{-} \leq \mathrm{a}_{\mathrm{i}} \leq \mathrm{a}_{\mathrm{i}}{ }^{+}$(where $\mathrm{i}=0,1,2,3,4$ ) are given below, where $\mathrm{a}_{\mathrm{i}}{ }^{-}$and $\mathrm{a}_{\mathrm{i}}^{+}$are the lower bound and the upper bound for $a_{i}$ respectively. For fixed value of ' $\tau$ ' and ' $t_{d}$ ' , a perturbation in process gain $\mathrm{Kp}[(\mathrm{Kp}-\Delta \mathrm{Kp}) \leq$ $\mathrm{Kp} \leq(\mathrm{Kp}+\Delta \mathrm{Kp})]$ is substituted in the above coefficients and Kharitonov's equations are checked for stability using
Routh-Hurwitz method. Similarly perturbation in ' $t_{d}$ ' (when $\mathrm{Kp}$ and ' $\tau$ ' fixed) and ' $\tau$ ' (when $\mathrm{Kp}$ and $\mathrm{t}_{\mathrm{d}}$ fixed) is evaluated and the stabiltiy ranges are recorded as shown in table below.

TABLE V Stability region for $\mathrm{Kp}, \tau$ and td with pid Controller (theorotical results)

\begin{tabular}{|c|c|c|c|}
\hline Method & Kp & $\boldsymbol{\tau}$ & $\mathbf{t}_{\mathbf{d}}$ \\
\hline Proposed & \pm 0.40 & \pm 0.25 & \pm 0.20 \\
\hline Huang-Chen & \pm 0.28 & \pm 0.25 & \pm 0.10 \\
\hline IMC & \pm 0.30 & \pm 0.15 & \pm 0.5 \\
\hline Visioli & \pm 0.10 & \pm 0.12 & \pm 0.5 \\
\hline
\end{tabular}

TABLE VI Stability region for Kp, $\tau$ and td with PID Controller (Simulated results)

\begin{tabular}{|l|l|l|l|}
\hline Method & Kp & T & Td \\
\hline Proposed & \pm 0.43 & \pm 0.32 & \pm 0.22 \\
\hline Huang-Chen & \pm 0.28 & \pm 0.30 & \pm 0.15 \\
\hline IMC & \pm 0.35 & \pm 0.18 & \pm 0.10 \\
\hline Visioli & \pm 0.15 & \pm 0.10 & \pm 0.13 \\
\hline
\end{tabular}

From Table V and Table VI we can conclude that the stability region for the PID conroller designed by the Proposed method[1] is more than the controllers designed by Visioli[3], Huang-Chen[2] and IMC method(Wang/Hang)[5]. The Simulation results results presented above validate the theorotical results.

\section{CONCLUSION}

The Stability and robustness analysis of the controllers concludes that the proposed method of PID controller design for Unstable FOPTD systems, gives a Robust and Stable response for uncertainty in process model parameters. Also the Proposed controller has a good disturbance rejection property thus resulting in a controller with good Regulatory and Servo response.

\section{REFERENCES}

[1] Padma Sree,R ., Srinivas,M.N .,Chidambaram,M ., A simple method of tuning PID controllers for stable and unstable FOPTD systems, Computers and Chemical Engineering 28,(2004),2201-2218.

[2] Huang, H. P., Chen, C. C., Control system synthesis for open loop unstable processes with delay. IEE Proceedings on the CTA,(1997), 144,334 .

[3] Visioli, A., Optimum tuning of PID controllers for integrating and unstable processes. IEE Proceedings on the CTA,(2001) 148, 180.

[4] Ross Barmish, B., A Generalization of Kharitonov's FourPolynomial Concept for Robust Stability Problems with Linearly dependent Coefficient perturbations, IEEE Transactions on Automatic Control. February 1989, Vol. 34, No.2.

[5] Wang, Q. C., Hang, C. C., Yang, X. P., Single loop controller design via IMC principles. Automatic,(2001) 37, 2041.

[6] Wayne Bequette, B., Process Control: Modeling, Design and Simulation, Pearson Prentice Hall, 2003.

[7] Shinskey,F.G., Feedback Controllers for the Process Industries, McGraw-Hill,Inc., 1994.

[8] Chidambaram, M., Applied process control. New Delhi: Allied Publishers,(1998) 